\title{
Simultaneous Supratentorial and Infratentorial Pilocytic Astrocytomas in an Adult Patient with Concurrent Neurofibromatosis Type 1 and HIV Infection
}

\section{Dalila Forte ${ }^{7}$, Anabela Nabais ${ }^{1}$, Carlos Pontinha ${ }^{2}$, Manuela Mafra' $^{2}$, Luís Mateus ${ }^{1}$}

\author{
Key words \\ - HIV infection \\ - IDH1 wild-type glioma \\ - Multicentric pilocytic astrocytoma \\ - Multiple pilocytic astrocytoma \\ - Neurofibromatosis type 1
}

\begin{abstract}
Abbreviations and Acronyms
AIDS: Acquired immunodeficiency syndrome

CNS: Central nervous system

HIV: Human immunodeficiency virus

MRI: Magnetic resonance imaging

NF1: Neurofibromatosis type 1

PA: Pilocytic astrocytoma

From the ${ }^{1}$ Neurosurgery Department and ${ }^{2}$ Pathology Department, Centro Hospitalar de Lisboa Central, Lisbon, Portugal

To whom correspondence should be addressed: Dalila Forte, M.D.

[E-mail: dalila.forte@gmail.com]

- Supplementary digital content available online. Citation: World Neurosurg. (2018) 117:172-177. https://doi.org/10.1016/j. wneu.2018.06.011 Journal homepage: www.WORLDNEUROSURGERYorg Available online: www.sciencedirect.com

1878-8750/\$ - see front matter () 2018 Elsevier Inc. All rights reserved.
\end{abstract}

\section{INTRODUCTION}

Neurofibromatosis type I (NFI) is an autosomal dominant genetic disorder resulting from a germline mutation in the $\mathrm{NF}_{1}$ gene. Located on chromosome 17qII.2, the NF1 gene encodes the tumorsuppressor protein neurofibromin, which is widely expressed throughout the nervous system. NFI is a predisposing condition to the development of benign and malignant tumors of the central nervous system (CNS). ${ }^{\mathrm{I}}$ Roughly $15 \%-20 \%$ of patients with NFI will develop low-grade gliomas, with approximately $80 \%$ located in the optic pathway, $15 \%$ in the brainstem, and the remaining $5 \%$ in the cerebellum, cerebral cortex, and subcortical regions. ${ }^{2}$ Pilocytic astrocytoma (PA), the most common CNS tumor associated with $\mathrm{NFI}{ }^{3}$ usually exhibits less aggressive biological behavior than its counterparts in patients without NFr. ${ }^{4}$

BACKGROUND: Neurofibromatosis type 1 (NF1) has been identified as a predisposing factor in the development of pilocytic astrocytoma (PA), a common benign central nervous system tumor. Although this is a common association, simultaneous development of multiple lesions is an infrequent finding, especially in nonoptic and hypothalamic locations.

CASE DESCRIPTION: A 41-year-old female patient with NF1 and uncontrolled human immunodeficiency virus (HIV) type 1 infection presented with a first generalized seizure and associated headache and ataxia. Imaging studies revealed 2 large intra-axial PAs, nodular-cystic in the supratentorial compartment and solid in the infratentorial compartment. Both lesions were treated by gross total resection in 2 surgeries performed 1 week apart. Despite their different imaging patterns, the tumors were histologically and genetically identical.

CONCLUSIONS: We present a unique case involving 2 histologically and genetically identical PAs occurring simultaneously in supratentorial and infratentorial locations. We suggest that an intrinsic predisposition to tumor development in patients with NF1 might have been enhanced by the HIV-related immunosuppression in this case. Strict oncologic surveillance is essential in patients with a tumor predisposition syndrome combined with immunosuppression.

Radiologic manifestations of PAs are varied. Two-thirds of all PAs exhibit a classic appearance, a cystic mass with an enhancing mural nodule; however, less common and nonspecific radiologic features are possible. In many cases, incongruence between imaging and histology is apparent, and PAs may present with imaging features typically seen in highergrade lesions. ${ }^{5}$ Presentation as multiple lesions, occurring simultaneously or separated in time, has been described in case reports and small series.

Glial tumours occurring in patients with human immunodeficiency virus (HIV) infection/acquired immunodeficiency syndrome (AIDS) have seldom been reported in the literature as case reports. ${ }^{6}$ To date, only I case of PA located subcortically in the left parietal-occipital region has been reported, by Gasnault et al. ${ }^{7}$ in 1988 .

\section{CASE PRESENTATION}

A 4I-year-old female patient presented to the emergency department after a first generalized tonic-clonic seizure, which subsided after endovenous administration of diazepam. She also had been experiencing headache, unsteadiness, and blurred vision over the previous 2 weeks. She had been diagnosed with HIV-I infection I3 years earlier and had arbitrarily suspended antiretroviral therapy, allegedly due to gastrointestinal intolerance. During childhood, she had undergone dystrophic scoliosis corrective surgery, and I year before the present admission, she had been diagnosed with a multifocal low-grade gastrointestinal stromal tumor of the jejunum-ileum after an endoscopic partial enterectomy, tumor resection, and anastomosis. General examination revealed multiple café-aulait spots and cutaneous neurofibromas. Neurologic examination was positive for left hemiataxia. Fundoscopic examination was normal. Laboratory workup revealed absolute and relative lymphocytopenia, with a $\mathrm{CD}_{4}$ cell count of $\mathrm{I} 58 / \mathrm{mm}$ (I0.3\%) and an HIV-I viral load of I2.176 (4.09 logs). Cranial computed 


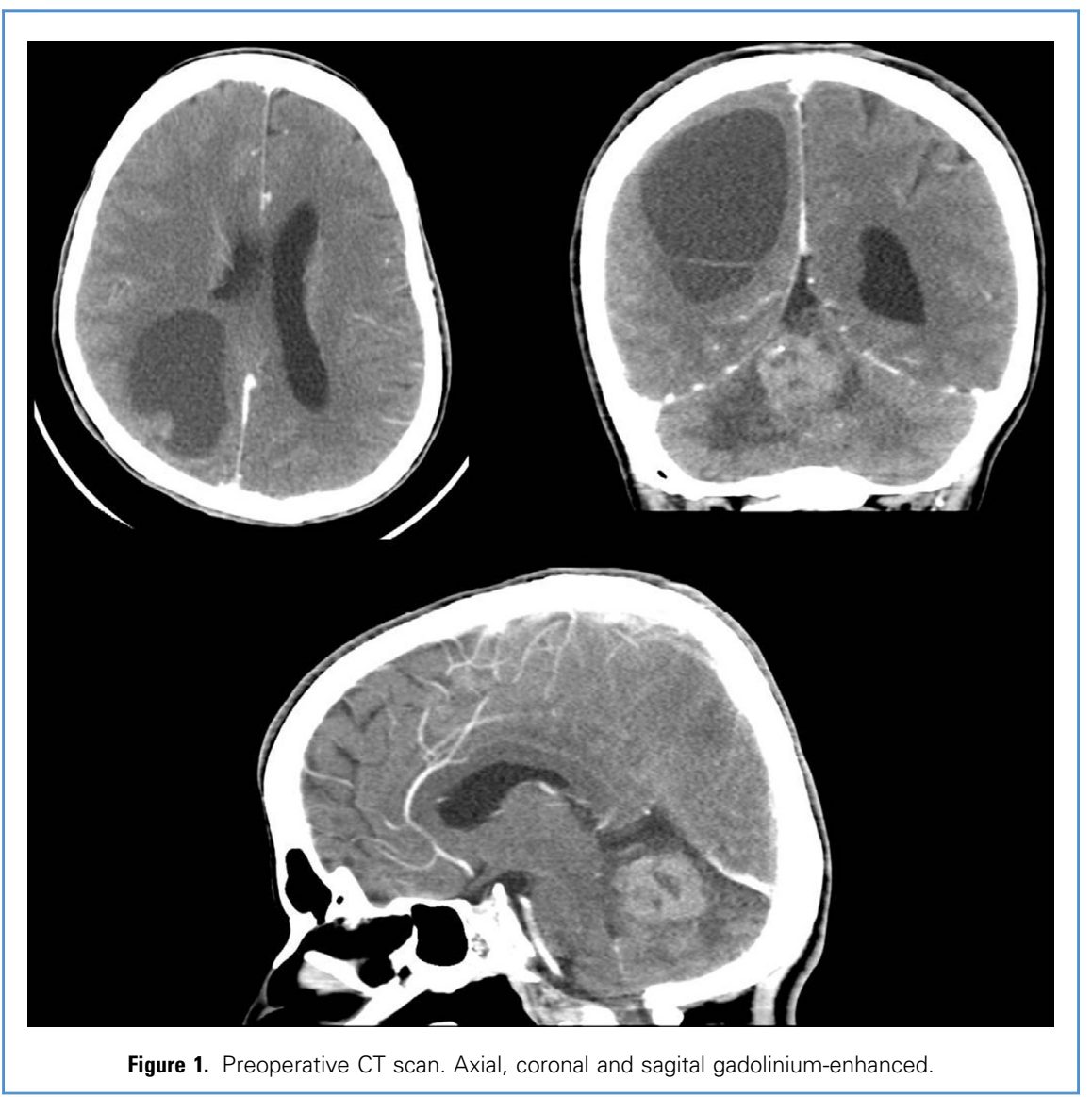

tomography (Figure 1) scan and MRI (Figure 2; Supplementary Data 1 and 2) showed 2 large intra-axial lesions: a supratentorial right subcortical parietal cystic lesion with an inferior enhancing mural nodule measuring approximately $59 \times 39 \times 60 \mathrm{~mm}$ and an infratentorial solid homogeneously enhancing vermian lesion measuring $23 \times 29 \times 28 \mathrm{~mm}$ with mild mass effect over the fourth ventricle, with no associated hydrocephalus. Spine MRI revealed no further lesions.

Two surgeries were performed I week apart: parieto-occipital craniotomy and total removal of the inferior solid nodule and drainage of a yellowish cystic component, followed by midline suboccipital craniotomy and gross total resection of a hard, solid lesion via a transvermian approach. Both procedures were uneventful. Histological analysis of the solid component of the supratentorial lesion showed elongated bipolar fusiform neoplastic cells mixed with
Rosenthal fibers and granular eosinophilic bodies. Immunohistochemistry was positive for glial fibrillary acidic protein and negative for $\mathrm{p}_{53}$ and revealed a low proliferative index (Ki-67/MIB-I), $\pm 2 \%$ (Figure 3). Histological analysis of the infratentorial lesion showed neoplastic cells with astrocytic morphology mixed with Rosenthal fibers, granular eosinophilic bodies, and mild perivascular lymphocytic infiltrate. Immunohistochemistry was again positive for Glial fibrillary acidic protein and negative for $\mathrm{p}_{53}$ and revealed a low proliferative index (Ki-67/MIB-I), < $1 \%$ (Figure 4). Histological diagnosis was consistent with PA (grade I, WHO) for both lesions. A genetic sequencing study yielded identical results, with no IDH1 exon 4 or BRAF exon I5 mutation present. No BRAF-KIAA 1549 fusion was found.

Immediate imaging showed no signs of complications, and the patient was discharged with only mild visual impairment. Genetic testing for NFI was positive. Antiretroviral therapy was reintroduced during hospital admission, and she resumed follow-up appointments for AIDS treatment with adequate immunologic and viral control. After 3 years, she remained clinically stable without further symptoms, except for mildly impaired visual acuity (right, 8/10; left, 9/ro), with otherwise normal ophthalmologic examination. A control MRI (Figure 5) at 3 years postsurgery showed a small stable residual infratentorial lesion. She is scheduled for annual neuraxis MRI imaging surveillance.

\section{DISCUSSION}

The terms "multicentric" and "multifocal" have been used interchangeably to classify

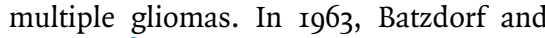
Malamud $^{8}$ suggested a classification that allows the distinction between the 2 


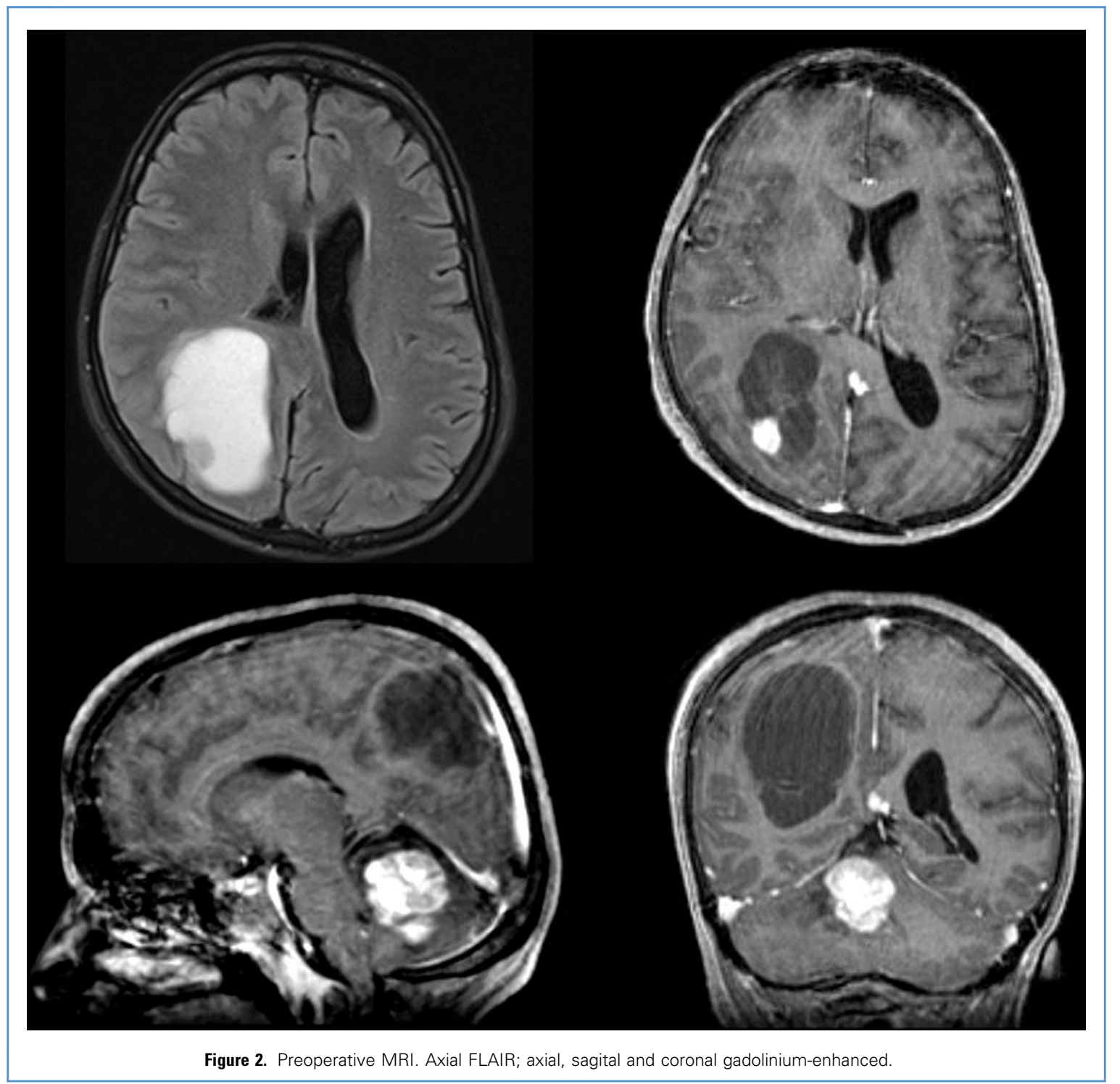

entities. Multifocal gliomas refers to 2 or more CNS tumors resulting from dissemination or growth via an established route, spread via white matter pathways, cerebrospinal fluid channels, or local metastasis, whereas multicentric gliomas are well-separated lesions in different lobes or hemispheres without anatomic continuity between them, which do not have a clear etiology through the aforementioned pathways.

The presentation of PAs as multiple lesions, although infrequent, is an acknowledged radiologic feature. The most common form is leptomeningeal dissemination, ${ }^{9-\text { II }}$ followed by smaller nodules spread through the neuroaxis associated with main lesions preferentially located in the optic pathway ${ }^{12-15}$ or cerebellum. ${ }^{\mathrm{IO}, \mathrm{I} 6}$ Rare cases of multiple intraventricular lesions ${ }^{17,18}$ have been described, as has a unique case of multiple extramedullary spinal nodules without intracranial disease. ${ }^{\text {I9 }}$ All the previously reported cases reflect probable dissemination through cerebrospinal fluid or white mater pathways, classifying them as multifocal APs according to Batzdorf and Malamud. Ogura et al. ${ }^{20}$ reported a I2-year-old patient with NFI presenting with simultaneous wellcircumscribed pineal and optic pathway PAs. Given the lack of an obvious dissemination route, this case should be classified as a multicentric lesion. Applying the same terminology, we classify our present case as a multicentric PA, because the lesions are well circumscribed and separated by the tentorium, with no obvious anatomic continuity between them.

The pathogenesis of multicentric gliomas remains unclear. Willis ${ }^{2 I}$ proposed that multicentric lesions may result from a 2-step process: I) initiation, in 

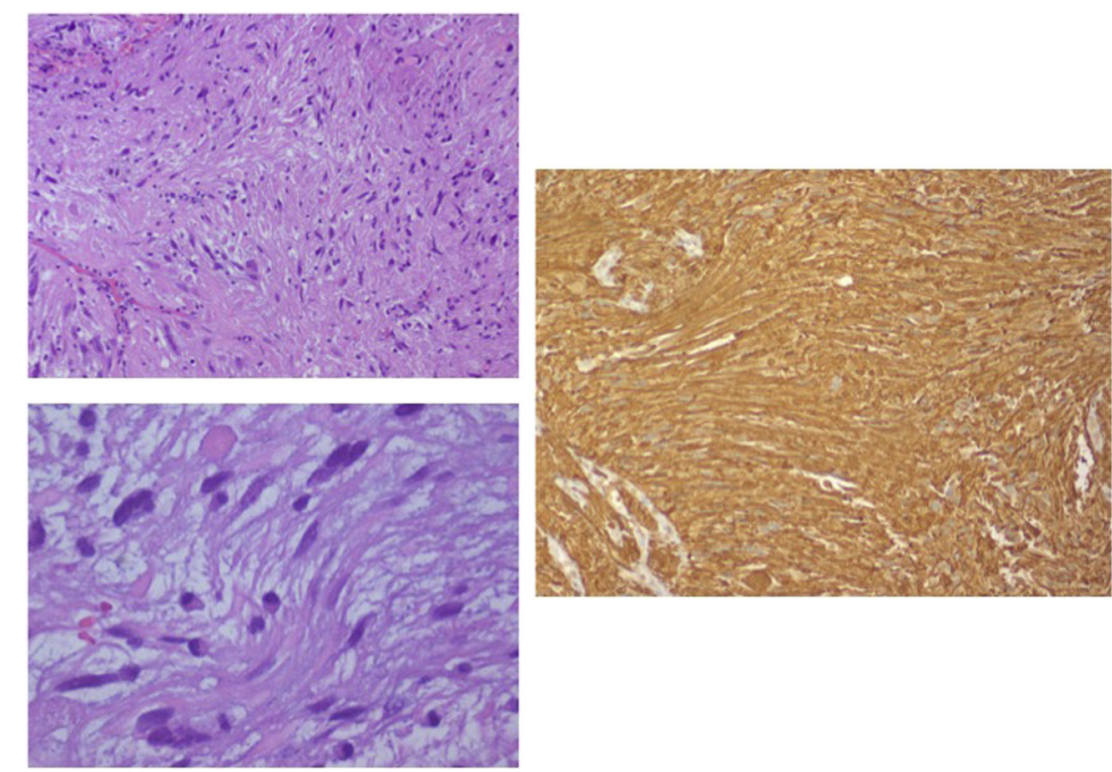

Figure 3. Parietal pilocytic astrocytoma. Biphasic tumor areas consisting of compact and loosely arranged tumor cells with mild pleomorphism associated with Rosenthal fibers and granular eosinophilic bodies. Strong glial fibrillary acidic protein staining confirms the astrocytic nature of the tumor. which a large area of the brain undergoes more susceptible to neoplastic growth, and 2) promotion, in which neoplastic

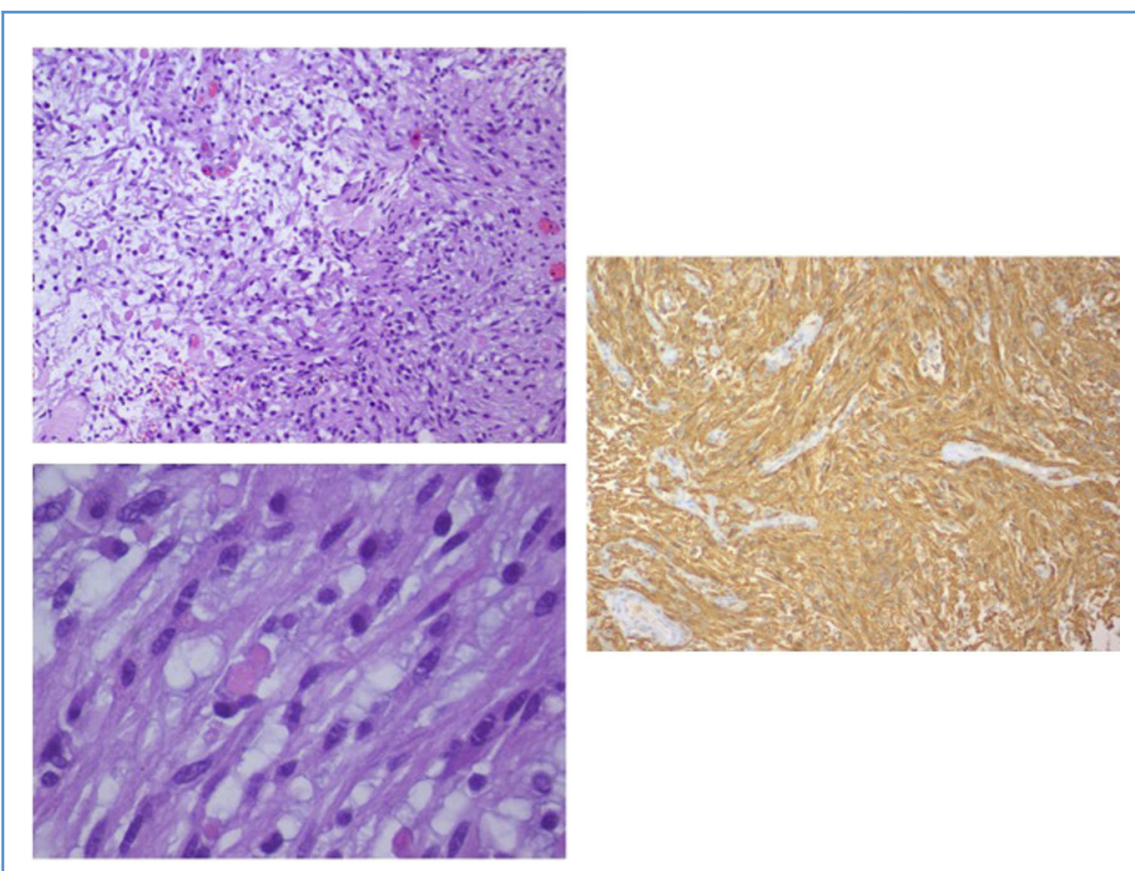

Figure 4. Cerebellar pilocytic astrocytoma. Neoplastic cells, glial fibrillary acidic protein-positive, with elongated "hair-like" processes mixed with Rosenthal fibers. neoplastic transformation, becoming proliferation in multiple sites occurs after various stimuli (biochemical, hormonal, mechanical, or viral). Zulch ${ }^{22}$ proposed that multicentricity may be due to metastasis along some presently unknown pathway.

Several factors might help explain the atypical biological behavior of PAs in the present case:

- Predisposition owing to NFI background. NFI has been identified as predisposing to the occurrence of multiple gliomas. ${ }^{23}$ The loss of neurofibromin protein results in hyperactivation of the Ras pathway, increasing the risk of developing tumors of the central and peripheral nervous systems. ${ }^{24}$

- HIV infection. To date, 26 cases of HIV infection/AIDS-related gliomas have been reported, only I of which was diagnosed as PA. ${ }^{6}$ The underlying pathogenesis of this phenomenon remains poorly understood. An indirect effect through disruption of the immune system is possible, impairing 3 processes involved in immune-mediated tumour suppression: elimination, or immunosurveillance, in which immunity functions as an extrinsic tumor suppressor; equilibrium, in which the immune system inhibits the expansion of transformed cells; and escape, in which tumor cells multiply as they become less immunogenic. ${ }^{25}$ Nef, a viral protein persistently expressed in brain astrocytes of patients with AIDS, might mediate a more direct effect of the virus, given its ability to transform glial cells both in vitro and in vivo. ${ }^{26}$ In addition, HIV is believed to enter the CNS and possibly infect neurons and astrocytes binding at $\mathrm{CCR}_{5}$ and $\mathrm{CXCR}_{4}$ receptors, which are present both in these cells and in macrophages. $^{6}$

- Specific tumor genetic profile. IDH1 mutations were absent in both tumors in this case. Recent findings suggest that multicentric gliomas might exhibit different genetic profiles than solitary lesions. In a genetic analysis of I4 patients with multicentric gliomas, although only 4 were classified as low-grade, all were consistently negative for mutant $\mathrm{IDH} 1$, suggesting that multicentric gliomas exhibit characteristics related to their mutant IDH1 negativity that differ from those of mutant IDH1 gliomas. ${ }^{27}$ In addition, IDHI/2 wild-type status is recognized to be associated with worse prognosis in patients with gliomas. ${ }^{28}$ 


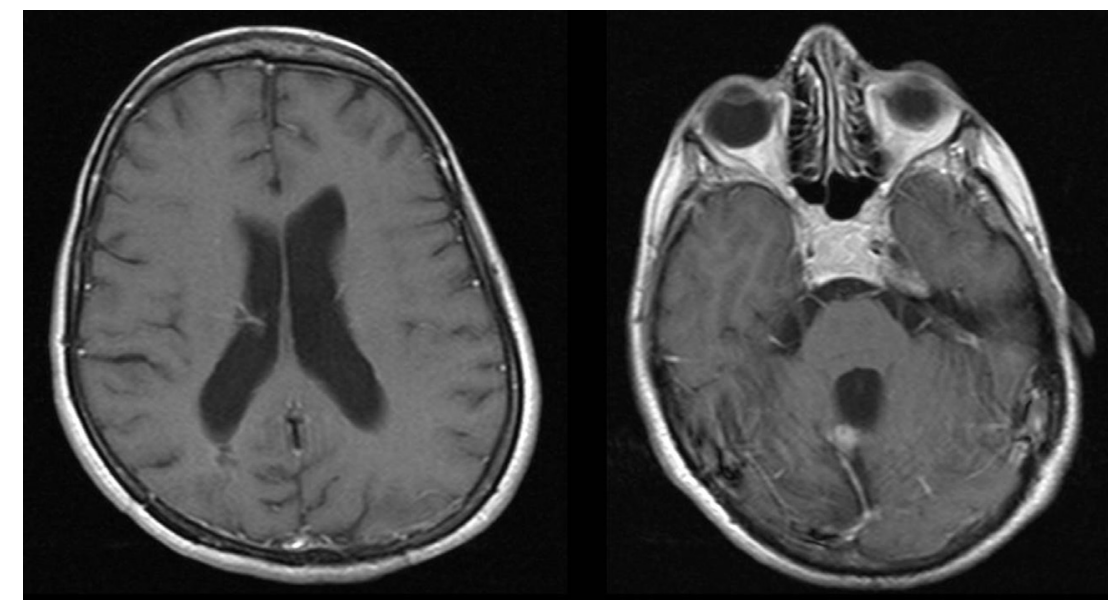

Figure 5. Postoperative MRI. Axial gadolinium-enhanced.

Several factors have been identified as prognostic for CNS tumors in patients with NFI. Survival is inversely correlated with adulthood and extraoptic location. ${ }^{4}$ Thus, this patient should be considered at high risk of recurrence/progression, and follow-up should include more frequent clinical and imaging assessments than are generally recommended for patients with completely surgically resected PAs.

\section{CONCLUSIONS}

To the best of our knowledge, this is the first documented case involving 2 histologically and genetically identical PAs presenting simultaneously in the supratentorial and infratentorial compartments. We suggest that in this particular case, intrinsic CNS tumor development predisposition was associated with NFI; HIVrelated immunosuppression, potential oncogenic properties, and a specific tumor genetic profile might have contributed to this unusual presentation. Strict oncologic surveillance of patients with tumour predisposition syndromes combined with immunosuppressive therapy is recommended.

\section{REFERENCES}

I. Karajannis MA, Ferner RE. Neurofibromatosisrelated tumors: emerging biology and therapies. Curr Opin Pediatr. 2015;27:26-33.

2. Hirbe AC, Gutmann DH. Neurofibromatosis type I: a multidisciplinary approach to care. Lancet Neurol. 20I4;13:834-843.
3. Al-Otibi M, Rutka J. Neurosurgical implications of neurofibromatosis Type I in children. Neurosurg Focus. 2006;20:E2.

4. Guillamo IS, Créange A, Kalifa C, Grill J, Rodriguez D, Doz F, et al. Prognostic factors of CNS tumours in neurofibromatosis I (NFI): a retrospective study of 104 patients. Brain. 2003; I26(Pt I):I52-I60.

5. Chourmouzi D, Papadopoulou E, Konstantinidis M, Syrris V, Kouskouras K, Haritanti A, et al. Manifestations of pilocytic astrocytoma: a pictorial review. Insights Imaging. 20I4; $5: 387-402$.

6. Chaudhry NS, Ahmad FU, Blieden C, Benveniste RJ. Brainstem anaplastic glioma in patients with AIDS: a case report and review of the literature. BMJ Case Rep. 2013:2013.

7. Gasnault J, Roux FX, Vedrenne C. Cerebral astrocytoma in association with HIV infection. J Neurol Neurosurg Psychiatry. I988;51:422-424.

8. Batzdorf U, Malamud N. The problem of multicentric gliomas. J Neurosurg. 1963;20:122-136.

9. Zorlu F, Selek U, Akyuz C, Ozturk A, Soylemezoglu F, Akalan N. Spinal seeding of a pilocytic astrocytoma following multiple subtotal resections. Pediatr Neurosurg. 2005;41:248-252.

Io. Mishima K, Nakamura M, Nakamura $\mathrm{H}$, Nakamura O, Funata N, Shitara N. Leptomeningeal dissemination of cerebellar pilocytic astrocytoma. Case report. J Neurosurg. I992;77: 788-791.

II. Figueiredo EG, Matushita H, Machado AG, Plese JPP, Rosemberg S, Marino R Jr. Leptomeningeal dissemination of pilocytic astrocytoma at diagnosis in childhood: two cases report. Arq Neuropsiquiatr. 2003;61:842-847.

I2. Yecies D, Fisher PG, Cheshier S, Edwards M, Grant G. Long-term outcomes of primarily metastatic juvenile pilocytic astrocytoma in children. J Neurosurg Pediatr. 2018;21:49-53.

13. Faria AV, Azevedo GC, Zanardi VA, Ghizoni E, Queiroz LS. Dissemination patterns of pilocytic astrocytoma. Clin Neurol Neurosurg. 2006;108: 568-572.

I4. Mamelak AN, Prados MD, Obana WG, Cogen PH, Edwards MS. Treatment options and prognosis for multicentric juvenile pilocytic astrocytoma. J Neurosurg. I994;8I:24-30.

I5. Matsumoto $\mathrm{T}$, Uekusa $\mathrm{T}$, Abe $\mathrm{H}$, Fukuda $\mathrm{Y}$, Mizutani Y, Oikawa S, et al. Multicentric astrocytomas of the optic chiasm, brain stem and spinal cord. Acta Pathol Jpn. I989;39:664-669.

I6. Jandaghi $\mathrm{AB}$, Bidabadi E, Saadat S, Alijani B, Daliri S, Reyhanian Z, et al. Leptomeningeal dissemination of pilocytic astrocytoma in a 17 year-old boy. Turk Neurosurg. 20I4;24:978-98I.

17. Sim KB, Hong SK. Multicentric juvenile pilocytic astrocytoma occurring primarily in the trigone of the lateral ventricle. Childs Nerv Syst. I999;I5: 477-48I.

I8. Xia J, Yin B, Liu L, Lu Y, Geng D, Tian W. Imaging features of pilocytic astrocytoma in cerebral ventricles. Clin Neuroradiol. 20I6;26:34I-346.

I9. Basheer A, Rammo R, Kalkanis S, Felicella MM Chedid M. Multifocal intradural extramedullary pilocytic astrocytomas of the spinal cord: a case report and review of the literature. Neurosurgery. 2017;80:Ei78-Ei84.

20. Ogura T, Adachi JI, Nishikawa R, Hirose T, Matsutani M. Synchronous optic and pineal pilocytic astrocytomas in a paediatric patient with neurofibromatosis type I. Pediatr Neurosurg. 2004 40:30I-305.

2I. Willis RA. Pathology of Tumours. London, UK: Butterworth; I96o.

22. Zulch K. Brain Tumors: Their Biology and Pathology. New York, NY: Springer US; 1957.

23. Salvati M, Caroli E, Orlando ER, Frati A, Artizzu S, Ferrante L. Multicentric glioma: our experience in 25 patients and critical review of the literature. Neurosurg Rev. 2003;26:275-279.

24. Dunn IF, Agarwalla PK, Papanastassiou AM Butler WE, Smith ER. Multiple pilocytic astrocytomas of the cerebellum in a 17 -year-old patient with neurofibromatosis type I. Childs Nerv Syst. 2007;23:II9I-II94.

25. Koebel C, Vermi W, Swann JB, Zerafa N, Rodig SJ, Old LJ, et al. Adaptive immunity maintains occult cancer in an equilibrium state. Nature. 2007;450: 903-907.

26. Hall JR, Short SC. Management of glioblastoma multiforme in HIV patients: a case series and review of published studies. Clin Oncol (R Coll Radiol). 2009;2I:59I-597.

27. Karlowee V, Amatya VJ, Hirano H, Takayasu T, Nosaka R, Kolakshyapati M, et al. Multicentric glioma develops via a mutant IDHI-independent pathway: immunohistochemical study of multicentric glioma. Pathobiology. 2017;84:99-107. 
28. Yan H, Parsons D, Jin G, McLendon R, Rasheed B, Yuan W, et al. IDHI and IDH2 mutations in gliomas. N Engl J Med. 2009;360:765-773.

Conflict of interest statement: The authors declare that the article content was composed in the absence of any commercial or financial relationships that could be construed as a potential conflict of interest.

Received 12 March 2018; accepted 2 June 2018

Citation: World Neurosurg. (2018) 117:172-177.

https://doi.org/10.1016/j. wneu.2018.06.011
Journal homepage: www.WORLDNEUROSURGERY.org Available online: www.sciencedirect.com

1878-8750/\$ - see front matter (C) 2018 Elsevier Inc. All rights reserved. 